\title{
118 切替え制御によるテザー衛星の運動範囲保証 \\ Switching Control to Obtain a Safe Kinetic Region of a Tethered Satellite
}

O岡崎 将光（阪大） 正大塚敏之（阪大）

Masamitsu OKAZAKI and Toshiyuki OHTSUKA

Osaka University, 2-1 Yamadaoka, Suita-shi, Osaka

\begin{abstract}
A tethered satellite is connected with a string called tether to a mother ship. Since the tether cannot be pushed, the control tension is constrained to be nonnegative. Additionally, since the tether has flexibility, its analysis is difficult. Therefore it is difficult to guarantee that the tethered satellite does not collide with the mother ship, the tether does not twine, and so on. Nevertheless, it has not been discussed enough to guarantee safety. To operate the satellite safely avoiding aforementioned situations, we propose to give switching conditions for the control input. In this paper, we report about the switching control law and simulation results.
\end{abstract}

Key Words : Tethered Satellite, Switching Control, Safe Kinetic Region, Nonliner Receding Horizon Control

\section{1.はじめに}

テザーとは宇宙空間において䙡数の人工衛星などを結ぶひも のことである. テザーでつながれた衛星をテザー衛星といい, テザー衛星からなるシステムをテザー衛星システムという。こ のテザー衛星システムは宇宙ミッションにおいて重要な役割を 持っている. 応用例として異なる高度での空気密度や磁場の测 定, 物資の輸送などが考えられ，過去にもテザー衛星を用いた ミッションが行われている(1). しかしながら，テザーの解析の 難しさ，スペースデブリによるテザー切断の危険性などの課題 が数多くある。

実際，1996 年にイタリア宇宙事業団と NASA が共同で開発 した, テザー衛星のミッションが行われている(1). 目的はテ ザ一衛星で地球軌道のプラズマ懪境を研究し, 発電に使えるこ とを実証するというものだった。しかし，伸展中にテザーが切 断してミッションは失敗に終わった，原因はテザーで発生した 放電と燃焼によってテザーの大部分が焼失したためであった. また，テザーが切れるまでは不具合の前兆は見られなかったと も報告されている.

このことから，テザーの切断，あるいは絡まりといったこと はいつ生じるか分からないと言える. もし, テザーの切断が起 こると，テザーが母船に絡まったり，あるいは衛星が母船に衝 突するなどの危険がある，それにも関わらず，安全性を保証す ることに関しては末だ十分な検討がなされていない.そこで本 研究では, 仮にテザ一衛星の伸展・回収中にテザーの切断が起 こったとしても衛星と母船との衝突などは生じないという保証 を得ることを目的とする. 本稿では，テザーが切れたとしても 衛星が母船の高さに達しないということを保証する. そして, 保証を得るために制御入力に切替条件を与えることを提案する. その際, 保証を得るための条件は柔軟性を無視したモデルによ り導出するが，シミュレーションでの検証は柔軟性を考慮した モデル (2) を用いていることに注目されたい。また，本稿では 紙面の都合上, シミュレーション結果は回収制御についてのみ 示すことにする.

\section{2. テザー年星システム}

Fig.1のシステムを考える. 母船は半径 $R_{G}$, 角速度 $\Omega$ の円 軌道を周回しているものとする. 用いる座標系としては, 母船 を原点にとり, 母船の速度方向を $x$, 母船から地球の重力中心方

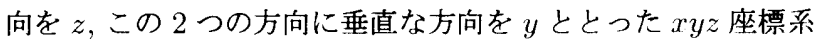
とする. 慣性系に対する角速度べクトルを $\boldsymbol{\omega}=[0-\Omega 0]^{\mathrm{T}}$, 衛 星の質量を $m$, 地球の質量を $M$, 万有引力定数を $G$ とする. 母船からとった衛星のベクトルを $\boldsymbol{r}_{s a t}(t)$, テザーの張力 (制御 入力) を $u(t)$ とすると, 衛星の運動方程式は次のようになる. ただし，I は単位行列， $\times$ (太字) は外積を表すものとする.

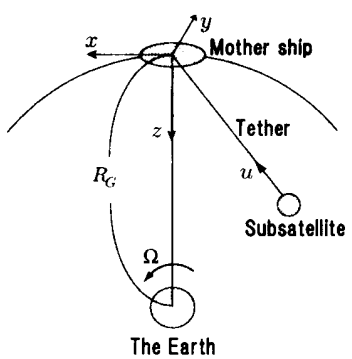

Fig. 1: tethered satellite system

$$
\begin{aligned}
m \frac{d^{2} \boldsymbol{r}_{\text {sat }}(t)}{d t^{2}}= & -G \frac{m M}{\left\|\boldsymbol{R}_{G}\right\|^{3}}\left(I-\frac{3 \boldsymbol{R}_{G} \boldsymbol{R}_{G}^{T}}{\left\|\boldsymbol{R}_{G}\right\|^{2}}\right) \boldsymbol{r}_{s a t}(t) \\
& -m \boldsymbol{\omega} \times\left(\boldsymbol{\omega} \times \boldsymbol{r}_{\text {sat }}(t)\right)-2 m \boldsymbol{\omega} \times \frac{d \boldsymbol{r}_{\text {sat }}(t)}{d t} \\
& -u(t) \frac{\boldsymbol{r}_{\text {sat }}(t)}{\left\|\boldsymbol{r}_{\text {sat }}(t)\right\|}
\end{aligned}
$$

次にこのモデルの状態方程式を導く. 軌道面外 $(y)$ 方向の運 動にも張力の影響は現れるが, 軌道面内 $(x z$ 面内) の運動とは 独立しており，テザー衛星の高度には影疃を与えないためここ では考えない，以降は軌道面内での運動に注目寸る。そこで， 状態量を $\boldsymbol{X}=\left[\begin{array}{llll}x & z & \dot{x} & \dot{z}\end{array}\right]^{\mathrm{T}}=\left[\begin{array}{lllll}X_{1} & X_{2} & X_{3} & X_{4}\end{array}\right]^{\mathrm{T}}$ とすると状態 方程式は次式のように導かれる. ただし， $r=\sqrt{X_{1}^{2}+X_{3}^{2}}$ で ある。

$$
\begin{gathered}
\dot{\boldsymbol{X}}=A(\boldsymbol{X})+B(\boldsymbol{X}) u \\
A(\boldsymbol{X})=\left[\begin{array}{c}
X_{3} \\
X_{4} \\
2 \Omega X_{4} \\
3 \Omega^{2} X_{2}-2 \Omega X_{3}
\end{array}\right], B(\boldsymbol{X})=\left[\begin{array}{c}
0 \\
0 \\
-X_{1} / m r \\
-X_{2} / m r
\end{array}\right]
\end{gathered}
$$

\section{3. 無次元入カー定のときの解析解}

制御入力はテザーの張力であるが，本稿では無次元化した入 力を考える. そこで，無次元化した入力を $\hat{u}$ とする. このとき 有次元入力 $u$ との関係は以下のようになる. また, テザーは押 すことが物理的に不可能なため入力は非負という拘束がある.

$$
u=m \| \boldsymbol{r}_{\text {sat }}|| \Omega^{2} \hat{u}, u, \hat{u} \geq 0
$$

このとき，状態方程式は次のように表せる。

$$
\dot{\boldsymbol{X}}=\left[\begin{array}{c}
X_{3} \\
X_{4} \\
2 \Omega X_{4}-X_{1} \Omega^{2} \hat{u} \\
3 \Omega^{2} X_{2}-2 \Omega X_{3}-X_{2} \Omega^{2} \hat{u}
\end{array}\right]
$$

日本機械学会〔No.03-8]第8回「運動と振動の制御」シンポジウム講演論文集〔2003.10.30～11.1·東京〕 
これは複雑な状態方程式ではないが，非線形なシステムなため 扱いが難しい，また，制御入力に拘束があるため，安全性を保 証することが難しく，どう保証するのかも問題となる．そこで， $\hat{u}$ を一定值にした場合，(1) 式は線形になり解析解が得られる のでそれを利用する. 具体的な保証方法については 4 節で述べ る. $\hat{u}=c$ (const.) としたとき, 状態方程式は次のようになる.

$$
\begin{gathered}
\dot{\boldsymbol{X}}=\boldsymbol{A} \boldsymbol{X} \\
=\left(\begin{array}{cccc}
0 & 0 & 1 & 0 \\
0 & 0 & 0 & 1 \\
-\Omega^{2} c & 0 & 0 & 2 \Omega \\
0 & \Omega^{2}(3-c) & -2 \Omega & 0
\end{array}\right)
\end{gathered}
$$

無次元入力を $\hat{u}=c$ と切り替えた瞬間の衛星の状態量を $\boldsymbol{X}_{0}=\left[\begin{array}{llll}x_{0} & z_{0} & \dot{x}_{0} & \dot{z}_{0}\end{array}\right]^{\mathrm{T}}$ とすると, 解析解は $\boldsymbol{X}(t)=e^{A t} \boldsymbol{X}_{0}$ と求 められる.ここで, $x(t)$ については母船の高度には関係ないた め，以降は $z(t)$ のみを考えていく.

まず，目標状態を平衡に保つための入力 $\hat{u}_{f}$ を求める．目標 状態を $\boldsymbol{X}_{f}=\left[\begin{array}{llll}0 & L_{f} & 0 & 0\end{array}\right]^{\mathrm{T}}$ とし，このとき $\dot{\boldsymbol{X}}=0$ を状態方程 式 (1) に代入すると $\hat{u}_{f}=3$ となる. 解析解 $z(t)$ は切り替える $c$ の值が $\hat{u}_{f}$ より大きいか小さいかによって形が変わる.

$c \geq \hat{u}_{f}$ のとき, $z(t)$ の解析解は次のようになる.

$$
z(t)=q_{1} \sin \left(\xi_{1} t+\theta_{1}\right)+q_{2} \sin \left(\xi_{2} t+\theta_{2}\right)
$$

ここで, $q_{1}, q_{2}, \xi_{1}, \xi_{2}, \theta_{1}, \theta_{2}$ は $c, \boldsymbol{X}_{0}$ により決まる定数であ る.この式から，原点を中心に振動することが分かる.つまり， 確塞に母船の高さに達してしまう.そこで， $c<\hat{u}_{f}$ の場合に限 定して考える.このときの解析解を下に示す.

$$
z(t)=F \sin \left(\zeta_{1} t+\phi\right)+\frac{h+k}{p} e^{\zeta_{2} t}+\frac{h-k}{p} e^{-\zeta_{2} t}
$$

ただし

$$
\begin{aligned}
p & =\Omega \sqrt{16 c+1}, \\
\zeta_{1} & =\Omega \sqrt{\frac{\sqrt{16 c+1}+1}{2}+c}, \zeta_{2}=\Omega \sqrt{\frac{\sqrt{16 c+1}-1}{2}-c} \\
h & =\frac{p+7 \Omega}{4} z_{0}-\dot{x}_{0}, k=\frac{\Omega^{2} c}{\zeta_{2}} x_{0}+\frac{p-\Omega}{4 \zeta_{2}} \dot{z}_{0} \\
F & =\sqrt{\left(\frac{(p-7 \Omega) z_{0}+4 \dot{x}_{0}}{2 p}\right)^{2}+\left(\frac{(p+\Omega) \dot{z}_{0}-4 \Omega^{2} c x_{0}}{2 p \zeta_{1}}\right)^{2}} \\
\phi & =\tan ^{-1} \frac{(p-7 \Omega) \zeta_{1} z_{0}+4 \zeta_{1} \dot{x}_{0}}{(p+\Omega) \dot{z}_{0}-4 \Omega^{2} c x_{0}}
\end{aligned}
$$

\section{4. 安全性の保証方法}

前節で求めた解析解をどのように利用して安全性を保証する のかを説明する.なお, Fig.2 はイメージ図である. 目的は安全 性を保証することであり, 本稿では $z(t) \geq a, \forall t \geq 0, a \geq 0$ を 保証することを考える. $a=0$ のときが母船の高さを意味する.

保証方法についてだが，まず，テザーが切れたとしても衛星 が $a[\mathrm{~m}]$ に達しないための状態量の範囲 (籁囲 A) を求める.こ の範囲内に衛星を常に留めておくことが目的となる. しかし，常 に留めておくということはできない (5 節参照). そこで, $\hat{u}=c$ の解析解を利用する. まず, $\hat{u}=c$ とした時の運動において, Fig.2 中の筑囲 A から出ないための状態量の範囲 (範囲 B) を求 める. 衛星が篹囲 B に含まれているときの入力は用いる制御則 に従い決定する．篹囲の境界に達したとき， $\hat{u}=c$ と入力を固 定する. 再び範囲 B に戻ってきたら制御則に従って入力を決定 する.このように入力の切替えを与えることにする.これによ り衛星を範囲 A に常に留めておくことができる.

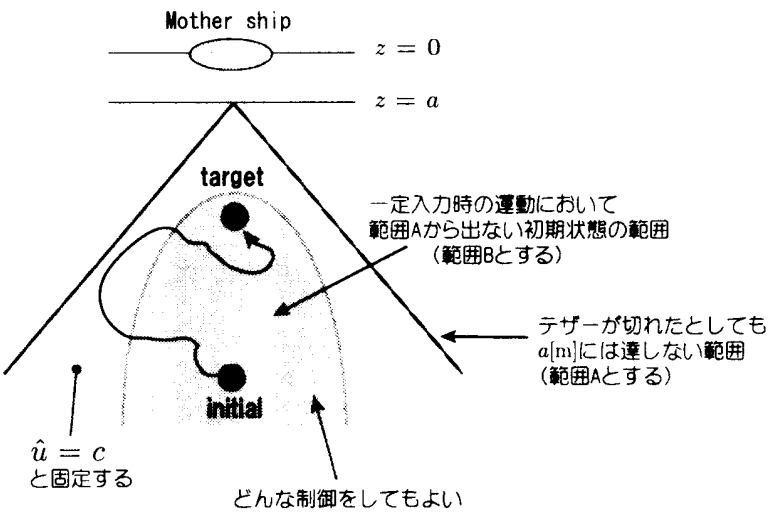

Fig. 2: the method for guarantee of safety

\section{5. テザー切断時の街星の通動}

テザーが切断した瞬間から衛星は自由運動を始めることにな る. このときの解析解はヒルの方程式 ${ }^{(3)}$ により次のように書 ける.

$$
\left\{\begin{array}{l}
x(t)=-\frac{2 \dot{z}_{0}}{\Omega} \cos \Omega t+\dot{x}_{0} t+x_{0}+\frac{2 \dot{z}_{0}}{\Omega} \\
z(t)=\frac{\dot{z}_{0}}{\Omega} \sin \Omega t+z_{0}
\end{array}\right.
$$

これより， $z(t) \geq a$ の十分条件は次のように求まる.

$$
\left|\dot{z}_{0}\right| \leq \Omega\left(z_{0}-a\right)
$$

したがって，常にテザーの切断を考虑するということは，以下 の式を満たすということである.

$$
|\dot{z}(t)| \leq \Omega(z(t)-a), \forall t \geq 0
$$

(3) 式が Fig.2 中の管囲 A に相当する. 常に満たさなければ ならないので，拘束条件として与えることが考えられる．そこ で，常に満たし続けることができるかを次のように調べた. (3) 式の右辺を移項して, $C(\boldsymbol{X}) \leq 0$ とおく. $C(\boldsymbol{X})=0$ のとき $\dot{C}(\boldsymbol{X}) \leq 0$ を満たす $\hat{u} \geq 0$ が存在するかを計算する. その結果, 入力 $\hat{u} \geq 0$ により $C(\boldsymbol{X}) \leq 0$ を満たし続けるには, 状热量は 次の条件のいずれかを満足しなければならないことが分かった。

条件 (a) $\quad C(\boldsymbol{X})<0$

条件 (b) $C(\boldsymbol{X})=0$ かつ $\dot{z} \geq 0$

条件 (c) $C(\boldsymbol{X})=0$ かつ $\dot{z}<0$ かつ $\dot{x} \leq \Omega z+\frac{\Omega a}{2}$

つまり, $C(\boldsymbol{X})=0$ の境界上で $\dot{z}<0$ かつ $\dot{x}>\Omega z+\Omega a / 2$ の とき, $C(\boldsymbol{X}) \leq 0$ を満たし続けることができない.したがって, 拘束条件として与えても破られる場合があるということが分か る.このことから，本稿で提案する切替え制御が有用であると 考える.

\section{6. テザー切断を考虑した保証条件}

6-1 保姃条件の算出 $\hat{u}=c$ の下で (3) 式を満たし続ける ための状態量 $\boldsymbol{X}_{0}$ の条件 (Fig.2の範囲 B に相当) を導出する. (2) 式を時間微分し，(3) 式に代入すると次のようになる.

$$
\begin{aligned}
& \text { - } \dot{z}(t) \geq 0 \text { のとき } \\
& \zeta_{1} F \cos \left(\zeta_{1} t+\phi\right)+\Omega F \sin \left(\zeta_{1} t+\phi\right) \\
& +\frac{h+k}{p}\left(\Omega+\zeta_{2}\right) e^{\zeta_{2} t}+\frac{h-k}{p}\left(\Omega-\zeta_{2}\right) e^{-\zeta_{2} t}-\Omega a \geq 0
\end{aligned}
$$




$$
\begin{aligned}
& \text { - } \dot{z}(t)<0 \text { のとき } \\
& -\zeta_{1} F \cos \left(\zeta_{1} t+\phi\right)+\Omega F \sin \left(\zeta_{1} t+\phi\right) \\
& +\frac{h+k}{p}\left(\Omega-\zeta_{2}\right) e^{\zeta_{2} t}+\frac{h-k}{p}\left(\Omega+\zeta_{2}\right) e^{-\zeta_{2} t}-\Omega a \geq 0
\end{aligned}
$$

(4), (5) 式が任意の時刻で成り立つための $\boldsymbol{X}_{0}$ の十分条件は次 のように導出できる.

$$
h+k \geq 0
$$

かつ

1. $\dot{z} \geq 0$ かつ $k \Omega+h \zeta_{2}<0$ のとき, および $\dot{z}<0$ かつ $k \Omega-h \zeta_{2}<0$ のとき

$$
\frac{2 \sqrt{\left(h^{2}-k^{2}\right)\left(\Omega^{2}-\zeta_{2}^{2}\right)}}{p}-F \sqrt{\Omega^{2}+\zeta_{1}^{2}} \geq \Omega a
$$

2. $\dot{z} \geq 0$ かつ $k \Omega+h \zeta_{2} \geq 0$ のとき, および $\dot{z}<0$ かつ $k \Omega-h \zeta_{2} \geq 0$ のとき

$$
\frac{2\left(h \Omega+k \zeta_{2}\right)}{p}-F \sqrt{\Omega^{2}+\zeta_{1}^{2}} \geq \Omega a
$$

(6)，(7)，(8) 式が Fig.2 中の簀囲 B に相当する，一定入力時 $(\hat{u}=c)$ におけるテザー切断を考虑した保証条件となる.

6-2 保证条件の包含閶係 (7)，(8) 式に包含関係が成り立っ ているのでそれを説明する. (7) 式の左辺第 1 項における根号 部分を見ると，

$$
\begin{aligned}
\sqrt{\left(h^{2}-k^{2}\right)\left(\Omega^{2}-\zeta_{2}^{2}\right)} & =\sqrt{(h \Omega)^{2}+\left(k \zeta_{2}\right)^{2}-\left(h^{2} \zeta_{2}^{2}+k^{2} \Omega^{2}\right)} \\
& \leq \sqrt{(h \Omega)^{2}+\left(k \zeta_{2}\right)^{2}} \\
& \leq \sqrt{(h \Omega)^{2}}+\sqrt{\left(k \zeta_{2}\right)^{2}} \\
& =h \Omega+k \zeta_{2}
\end{aligned}
$$

と表すことができる，よって，以下の関係が成り立つ.

$$
\frac{2 \sqrt{\left(h^{2}-k^{2}\right)\left(\Omega^{2}-\zeta_{2}^{2}\right)}}{p} \leq \frac{2\left(h \Omega+k \zeta_{2}\right)}{p}
$$

つまり，(7) 式が成り立てば，(8) 式も成り立つことが分かる. したがって，(6)，(7)の 2 式のみを保証条件として用いること もできる.しかし，これは (8) 式を用いない分，より蕨しい保 守的な条件となる.

衛星の状管量がこの保証条件を満たしている間は用いる制御 則によって入力を決定し, 境界に達した場合は無次元入力を一 定值にするという入力の切替則を与える.これにより，テザー がいつ切断しても $z(t) \geq a, \forall t \geq 0$ を保証することができる.

\section{7.シミュレーション}

7-1 制御手法 非線形システムを扱う制御則として，本稿 では非線形 Receding Horizon 制御 ${ }^{(4)}$ を用いる. 制御入力に は非負という不等式拘束があるので，ダミ一入力 $d$ を用いて等 式拘束に変換する.

$$
\hat{u} \geq 0 \Longleftrightarrow \hat{u}-d^{2}=0
$$

評価関数については次のように与える.ここで， $\boldsymbol{X}_{f}$ は目標状 態, $\boldsymbol{v}=[u, d]^{\mathrm{T}}, \boldsymbol{v}_{f}=\left[u_{f}, \sqrt{u_{f}}\right]^{\mathrm{T}}$ である. また, $\wedge$ は変数を 無次元化したものとする.

$$
\begin{aligned}
J= & \frac{1}{2}\left[\hat{\boldsymbol{X}}(t+T)-\hat{\boldsymbol{X}}_{f}\right]^{\mathrm{T}} S_{f}\left[\hat{\boldsymbol{X}}(t+T)-\hat{\boldsymbol{X}}_{f}\right] \\
& +\frac{1}{2} \int_{t}^{t+T}\left[\left(\hat{\boldsymbol{X}}-\hat{\boldsymbol{X}}_{f}\right)^{\mathrm{T}} Q\left(\hat{\boldsymbol{X}}-\hat{\boldsymbol{X}}_{f}\right)\right. \\
& \left.+\left(\hat{\boldsymbol{v}}-\hat{\boldsymbol{v}}_{f}\right)^{\mathrm{T}} R\left(\hat{\boldsymbol{v}}-\hat{\boldsymbol{v}}_{f}\right)\right] d t^{\prime}
\end{aligned}
$$

なお, $S_{f}, Q, R$ は適当な重みである.

7-2 回収制御 6 節の保証条件は柔軟性を無視したモデル から導出した，それは，柔軟性を考虑したモデルは運動方程式 が複雑なため, 保証条件を導出することが困奞なためである. そこで, 柔軟性を無視したモデルから得られた保証条件を用い, 柔軟性を考應したモデル ${ }^{(2)}$ でシミュレーションを行い, 有効 性を検証する。

シミュレーション結果を Fig.3, Fig.4 に示す. いま $a=$ $200[\mathrm{~m}]$ には達して欲しくない状況だとする．初期状態は， $\boldsymbol{X}_{0}=\left[\begin{array}{llll}0 & 900 & 0 & 0\end{array}\right]^{\mathrm{T}}$, 目標状態は $\boldsymbol{X}_{f}=\left[\begin{array}{llll}0 & 500 & 0 & 0\end{array}\right]^{\mathrm{T}}$ であ る. 重みは $S_{f}=10 I, Q=\left[\begin{array}{llll}0.1 & 10 & 0.1 & 0.1\end{array}\right]^{\mathrm{T}}, R=0.1 I(I$ は単位行列), 一定にする入力値は $c=2.6\left(\hat{u}_{f}=3\right)$, シミュ レーション時間はいずれも 15000 [sec] である. 各図において “initial” は初期位置, “target” は目標位置を表している. また, 切替えを行った図の破線部分は $\hat{u}=c$ と一定にしているところ である. Fig.3 (a) を見るとテザーが切れないとすれば安全と言 えるが，もし図中に示す $\mathrm{P}$ 点でテザーが切断されたとすると， Fig.3 (b) に示す通り $a=200[\mathrm{~m}]$ を大きく超えてしまう. 場合 によっては衛星が母船と衙突する危険すらある，そこで， 6 節 で導出した保証条件 (6)，(7)，(8) 式を付加する，そのときの 解軌道を Fig. 3 (c) に示す. 切替えを行わなかったときと比べ ると，違いは表れているがこの図だけではテザー切断をどう考 虑しているのか分からないので, Fig.4で説明する. Fig.4にお ける 2 直線の内側が (3) 式を意味する. つまり, 衛星の状態量 $(z, \dot{z})$ を 2 直楾の内側に留めておくことがテザー切断を考虑す ることになる. Fig.4 (a) は切替えを行わなかったとき, Fig.4 (b) は切替えを行ったときの結果である. Fig.4 (a)のP点のよ うに 2 直線の外側に出ている部分でテザーが切れると, 設定し た $a[\mathrm{~m}]$ の高さを確実に超えてしまう.Fig.4 (b) は 2 直線の内 側に状態量を留めることができているため, テザーがいつ切れ ても，設定した $a[\mathrm{~m}]$ の高さを超えることはない. また, Fig.3 (d), Fig.4 (c) は切替え条件として (6)，(7)の 2 式のみを用い たときの結果である.この場合も良好な結果が得られている.

\section{8. おわりに}

テザー衛星が母船に衝突するなどの危険を回避するため, 七 ルの方程式および無次元入力一定時の解析解を用いて制御入力 に与える切替条件を導出した．切替条件は柔軟性を無視したモ デルで導き，シミュレーションは柔軟性を考虑したモデルで行っ たが，良好な結果が得られた．また切替条件により，仮にテザー が切れて衛星が制御不能状態に宿っても，衛星が母船に衝突し たりすることはない.つまり, 衛星の運動範井が保証された.

\section{考支㙎}

(1) NASDA NEWS，海外宇宙情報，No. 174，No. 177, URL: http://www.nasda.go.jp/lib/nasda-news/1996/08/ back_j.html (1996)

（2）渡辺 大輔，大塚 敏之：柔軟性を考慮したテザ一衛星の軌道面外運 動に対する非線形 RH 制御，第 46 回システム制御情報学会研究 発表講演会講演論文集, pp. 49-50 (2002)

（3）木田 隆，小松 敬治，川口淳一郎：人工衛星と宇宙探査機, コ口 于社 (2001)

（4）大塚 敏之: 非線形 Receding Horizon 制御の計算方法について 計測と制御, Vol. 41, No. 5, pp. 366-371 (2002) 


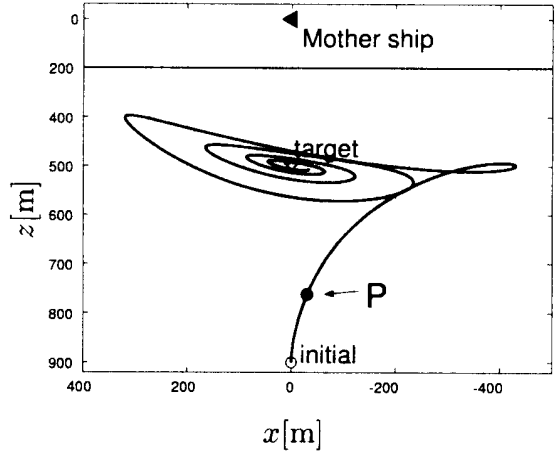

(a) without switch

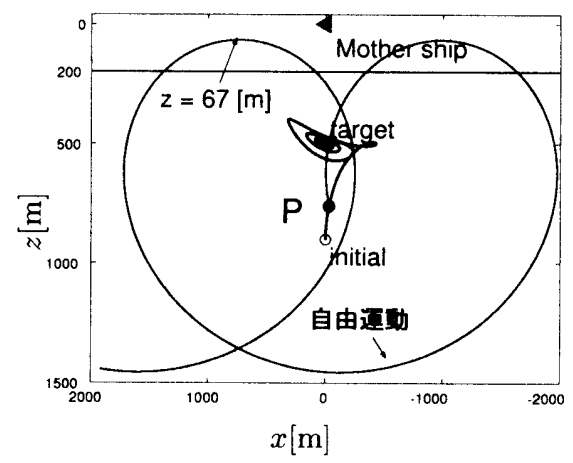

(b) when the tether cuts

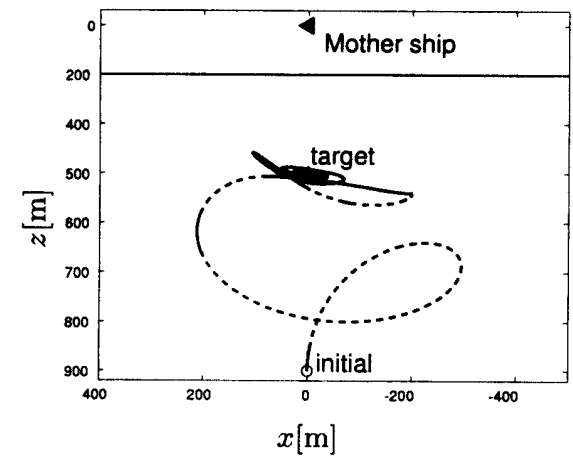

(c) with switch (3 switching conditions)

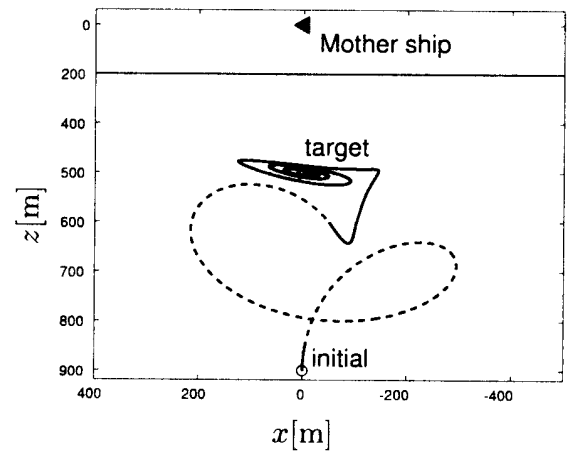

(d) with switch (2 switching conditions)

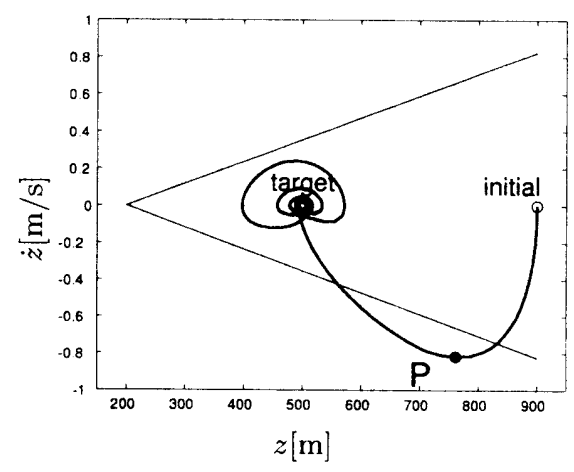

(a) without switch

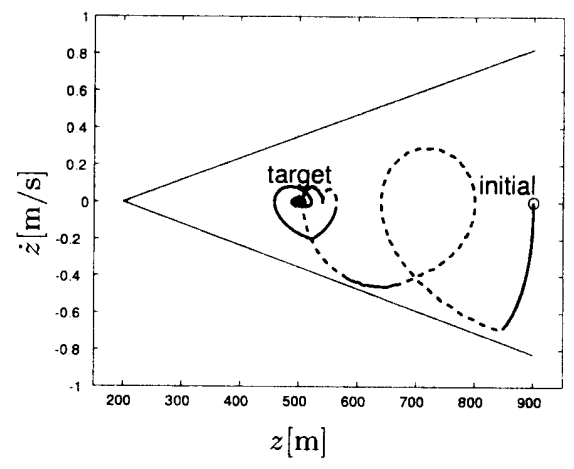

(b) with switch (3 switching conditions)

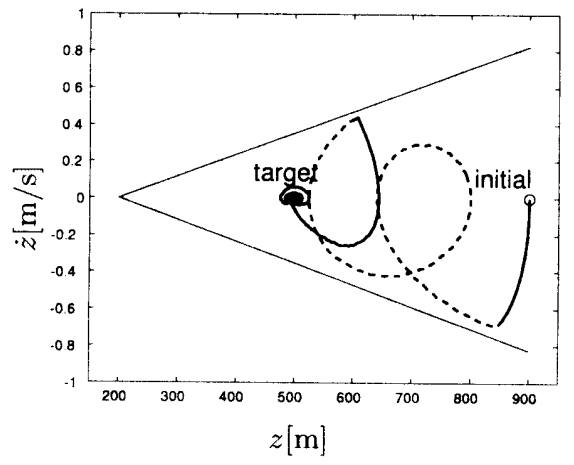

(c) with switch (2 switching conditions)

Fig. 4: $z-\dot{z}$ plane trajectories

Fig. 3: $x-z$ plane trajectories 